\title{
Prognostic Factors and Management for Left Colonic Perforation: Can Hartmann's Procedure Be Preventable?
}

\author{
Yilseok Joo, Yujin Lee, Taeyoung Yoo, Jungbin Kim, Inseok Park, Geumhee Gwak, Hyunjin Cho, Keunho \\ Yang, Kiwhan Kim, Byung-Noe Bae \\ Department of Surgery, Inje University Sanggye Paik Hospital, Seoul, Korea
}

Purpose: To identify factors significantly associated with the mortality of patients with left colonic perforation, and to compare the outcome of Hartmann's procedure (HP) and primary repair (PR) or primary anastomosis (PA) in patients with left colonic perforation without factors associated with mortality.

Methods: This retrospective study included patients who underwent surgery for left colonic perforation from January 2009 to February 2018. Preoperative factors related to postoperative mortality, including vital signs, laboratory findings, and intraoperative findings, were analyzed by type of operation. The chi-square, Fisher exact, and Mann-Whitney U-tests were used to analyze the data.

Results: Ninety-one patients were included (36 men, 55 women), and 15 (16.5\%) died postoperatively. Prognostic factors were age, leukopenia, thrombocytopenia, bleeding tendency, acute kidney injury, hemodynamic instability, and the existence of feculent ascites. Leukopenia and longer operative time were independent risk factors for mortality. Seventy-nine patients did not have leukopenia and 30 of these patients who underwent PR without diversion were excluded from the subanalysis. HP was performed in 30 patients, and PR with diversion and PA with or without diversion were performed in 19. Compared to the other operative methods, HP had no advantage in reducing hospital mortality $(\mathrm{P}=0.458)$ and morbidity.

Conclusion: Leukopenia could be an objective prognostic factor for left colonic perforation. Although HP is the gold standard for septic left colonic perforation, it did not improve the hospital mortality of the patients without leukopenia. For such patients, PR or PA may be suggested as an alternative option for left colonic perforation.

Keywords: Hartmann's procedure; Colon perforation; Postoperative mortality

\section{INTRODUCTION}

Most patients with left colonic perforation are diagnosed with peritonitis, which may lead to a life-threatening condition requiring emergent surgical management. The emergent surgery in response to the life-threatening condition is in itself associated with

Received: September 2, 2019 - Accepted: November 14, 2019

Correspondence to: Byung-Noe Bae, M.D.

Department of Surgery, Inje University Sanggye Paik Hospital, 1342 Dongil-ro, Nowon-gu, Seoul 01757, Korea

Tel: +82-2-950-1017, E-mail: bnbae@paik.ac.kr

ORCID: https://orcid.org/0000-0002-5542-5626

(C) 2020 The Korean Society of Coloproctology

This is an open-access article distributed under the terms of the Creative Commons Attribution NonCommercial License (https://creativecommons.org/licenses/by-nc/4.0) which permits unrestricted non-

commercial use, distribution, and reproduction in any medium, provided the original work is properly cited. high morbidity and mortality. Although there have been many advancements and innovations in the surgical technique and medicine, the mortality of patients with colonic perforation is still high $[1,2]$.

Hartmann's procedure (HP) was first introduced by Henry Albert Hartmann in 1921 during the 30th meeting of the French Surgical Association [3]. This procedure consists of a sigmoid colectomy with end colostomy and distal stump. The development of HP decreased the mortality rate of patients. For several decades, HP has been the standard emergent surgical procedure for treating left colonic perforation [4].

However, $\mathrm{HP}$ is associated with low quality of life (QoL) because of the colostomy care required [5], and restoration of intestinal continuity after HP is associated with its own morbidity and mortality $[3,6]$. The reversal rate of HP tends to be lower than $50 \%$ in most reported articles [3]. Recently, several studies have reported 
that primary repair (PR) or primary anastomosis (PA) can improve levels of morbidity and mortality compared with HP. However, other studies have reported that PR or PA had no beneficial effect on mortality and morbidity [7].

Considering the controversy of using HP in patients with left colonic perforation, we hypothesized that HP would exhibit a comparable outcome with PR or PA in a specific patient group with a low risk of mortality. If the group of patients that received no benefit from HP was known, this knowledge would lead to a decrease in the morbidity and mortality associated with the procedure. The primary goal of our study was to identify factors significantly associated with mortality in patients with left colonic perforation. The secondary goal was to compare the outcome of $\mathrm{HP}$ and PR or PA in left colonic perforation patients without factors associated with mortality.

\section{METHODS}

\section{Study design and patients}

The study protocol was approved by the Institutional Review Board (IRB) of Inje University Sanggye Paik Hospital (approval number: 2019-04-008). This retrospective study included patients who underwent surgery for colonic perforation from January 2009 to February 2018 in Inje University Sanggye Paik Hospital. Overall, 113 patients underwent a surgical procedure for the treatment of colonic perforation and 111 patients were selected owing to the fidelity of the data. Among these 111 patients, 91 had left colonic perforation and the remaining patients had right or transverse colonic perforation. The left colon was defined as the descending colon to the rectum. The IRB waived the need for informed consent in this retrospective chart review.

\section{Data collection}

All data were collected by reviewing the medical records of the patients. The data collected were patients' demographics (age, sex, weight, body mass index, and history of abdominal operation), clinical history (cause of perforation and the time from symptom onset to surgery), initial vital signs, preoperative laboratory findings, operative findings (perforation site, type of operation, aspect of ascites, and operative time), length of hospital stay, and existence of surgical site infection and newly developed postoperative complications.

Each factor was classified. We defined advanced age as older than 70 years. Hypotension was defined as systolic blood pressure lower than $90 \mathrm{mmHg}$. Heart rates were grouped as more than 90 beats/min and other. Fever was defined as a body temperature more than $37.8^{\circ} \mathrm{C}\left(100^{\circ} \mathrm{F}\right)$, and patients were grouped as having a fever of more than $37.8^{\circ} \mathrm{C}$ and $37.8^{\circ} \mathrm{C}$ or less. Anemia was defined as a hemoglobin level of less than $12.5 \mathrm{~g} / \mathrm{dL}$, as per the World Health Organization criteria for anemia [8]. Leukopenia was defined as a white blood cell count of less than $4,000 / \mathrm{mcL}$, as per systemic inflammatory response syndrome (SIRS) criteria [9]. Thrombocytopenia was defined as a platelet count lower than $100,000 / \mu \mathrm{L}$, according to the criterion for moderate thrombocytopenia by Williamson et al. [10]. An activated partial thromboplastin time prolongation of more than 60 seconds was regarded as having a bleeding tendency. A preoperative serum creatinine level of more than $2.0 \mathrm{mg} / \mathrm{dL}$ without a past history of chronic kidney disease was regarded as acute kidney injury. Hyponatremia and hypokalemia were defined as a serum sodium level lower than $135 \mathrm{meq} / \mathrm{L}$ and serum potassium level lower than $3.5 \mathrm{meq} / \mathrm{L}$, respectively. A partial pressure of carbon dioxide level lower than $32 \mathrm{mmHg}$ was regarded as tachypnea, according to the SIRS criteria [9]. Causes of perforation were categorized as benign (diver-

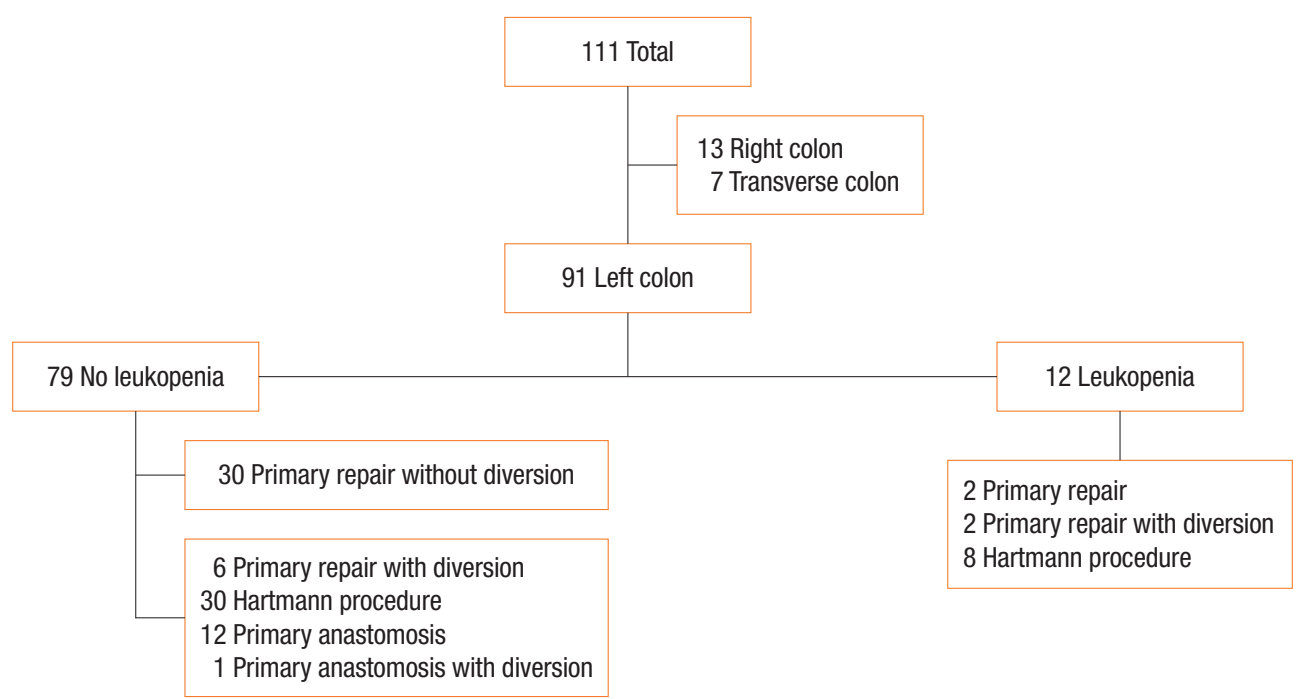

Fig. 1. Distribution of the patietns. 
ticulitis, colitis, and ischemia), malignancy, iatrogenic, trauma, and other. Preoperative use of inotropes or vasopressors was considered to indicate patients with hemodynamic instability.

\section{Subanalysis}

To compare HP with other operative methods in a moderate risk group, we excluded patients who had leukopenia because leukopenia was the only independently relevant prognostic factor for mortality of left colonic perforation. We also excluded patients who underwent PR without diversion because they had mild disease. Thus, this subanalysis included a group of patients at moderate risk, who underwent an operation except for PR without diversion and did not have leukopenia preoperatively. Forty-nine patients were included in the subanalysis. The flow chart of patients is presented in Fig. 1.

\section{Statistical analysis}

The chi-square test and Fisher exact test were used to analyze discrete variables. The Mann-Whitney U-test was used to analyze continuous variables. Relationships with postoperative in-hospital mortality were analyzed based on each data and the type of operation, and factors with a P-value less than 0.05 in the univariate analysis were evaluated in a logistic regression model for multivariate analysis. Odds ratios and 95\% confidence intervals were calculated with the chi-square test and logistic regression model. Statistical analyses were performed using IBM SPSS Statistics ver. 25.0 (IBM Co., Armonk, NY, USA). All reported P-values are 2 -tailed, and P-values $<0.05$ were considered statistically significant.

\section{RESULTS}

Overall, 91 patients were included in this study. Patient characteristics are presented in Table 1. The mean age of patients was $69.2 \pm 12.8$ years, and 36 patients were men. The most common cause of perforation was diverticulitis (30\%). HP (41\%) was the most frequently performed operation, and PR (35\%) was the second most commonly conducted operation.

Fifteen patients died during hospitalization, and the rate of inhospital mortality was $16 \%$. Preoperative patient characteristics such as advanced age, existence of leukopenia, thrombocytopenia, bleeding tendency, acute kidney injury, and hemodynamic instability were associated with in-hospital mortality (Table 2). Operative findings such as existence of feculent ascites and operative time were associated with in-hospital mortality. Comorbidity, cause of perforation, and type of operation were not statistically significant. HP was associated with a higher tendency of in-hospital mortality than other methods of operation, but this was not statistically significant. Multivariate logistic regression analysis showed that the existence of preoperative leukopenia and longer operative times were the most relevant factors associated with inhospital mortality (Table 2).
Table 1. Characteristics of the 91 patients who underwent surgery for left colonic perforation

\begin{tabular}{lc}
\hline Characteristic & Value \\
\hline Age (yr) & $69.2 \pm 12.8$ \\
Sex & \\
Male & $36(40)$ \\
Female & $55(60)$ \\
Hospital stay & \\
Fewer than 15 days & $35(38)$ \\
More than 15 days & $56(62)$ \\
Body mass index (kg/m²) & $23.2 \pm 3.1$ \\
History of abdominal operation & \\
No & $67(74)$ \\
Yes & $24(26)$ \\
Cause of perforation & \\
Benign cause & $57(63)$ \\
Cancer & $9(10)$ \\
latrogenic (CFS) & $16(18)$ \\
Trauma & $4(4)$ \\
Other & $5(5)$ \\
Type of surgery performed & \\
PR & $32(35)$ \\
PR with diversion & $8(9)$ \\
HP & $12(13)$ \\
PA & $1(1)$ \\
\hline
\end{tabular}

Values are presented as mean \pm standard deviation or number (\%).

CFS, colonofiberscopy; PR, primary repair; HP, Hartmann's procedure; PA, primary anastomosis.

Subanalysis was performed between the group that underwent $\mathrm{HP}(\mathrm{n}=30)$ and the group that underwent other operative methods such as PR with diversion $(n=6)$, PA only $(n=12)$, and PA with diversion $(n=1)$ (Fig. 1). In this subanalysis, preoperative and intraoperative findings such as acute kidney injury and feculent ascites showed no difference between the 2 groups. This finding may indicate that there was no preoperative difference in the severity of the disease. There was a lower tendency of postoperative ileus and a higher tendency of surgical site infections in the HP group compared with the PR or PA group. Anastomotic leakages were not confirmed in the other operative method group. There was no statistical difference in mortality and morbidity between the 2 groups (Table 3 ).

\section{DISCUSSION}

There are several studies about the prognostic factors associated 
Table 2. Analysis of in-hospital mortality

\begin{tabular}{|c|c|c|c|c|c|c|}
\hline \multirow{2}{*}{ Variable } & \multicolumn{2}{|c|}{ Univariate analysis } & \multirow{2}{*}{ P-value } & \multicolumn{2}{|c|}{ Multivariate analysis } & \multirow{2}{*}{ P-value } \\
\hline & Survivors $(\mathrm{n}=76)$ & Nonsurvivors $(n=15)$ & & Odd ratio & $95 \% \mathrm{Cl}$ & \\
\hline Age (yr) & & & $0.025^{*}$ & 3.39 & $0.40-29.27$ & 0.268 \\
\hline$\leq 70$ & $40(53)$ & $3(20)$ & & & & \\
\hline$>70$ & $36(47)$ & $12(80)$ & & & & \\
\hline Sex & & & 0.388 & & & \\
\hline Male & $32(42)$ & $4(27)$ & & & & \\
\hline Female & $44(58)$ & $11(73)$ & & & & \\
\hline Hypertension history & & & 0.078 & & & \\
\hline No & $29(38)$ & $2(13)$ & & & & \\
\hline Yes & $47(62)$ & 13(87) & & & & \\
\hline Diabetes mellitus history & & & 0.120 & & & \\
\hline No & $66(87)$ & $10(67)$ & & & & \\
\hline Yes & $10(13)$ & $5(33)$ & & & & \\
\hline Cerebrovascular accident history & & & 1.000 & & & \\
\hline No & $71(93)$ & 14(93) & & & & \\
\hline Yes & $5(7)$ & $1(7)$ & & & & \\
\hline Cardiovascular disease history & & & 0.359 & & & \\
\hline No & $69(91)$ & $12(80)$ & & & & \\
\hline Yes & $7(9)$ & $3(20)$ & & & & \\
\hline Chronic kidney disease history & & & 0.164 & & & \\
\hline No & 70 (92) & $12(80)$ & & & & \\
\hline Yes & $6(8)$ & $3(20)$ & & & & \\
\hline Heart rate (beats/min) & & & 0.404 & & & \\
\hline$\leq 90$ & $45(59)$ & $7(47)$ & & & & \\
\hline$>90$ & $31(41)$ & $8(53)$ & & & & \\
\hline Body temperature $\left(^{\circ}\right)$ & & & 0.762 & & & \\
\hline$\leq 37.8$ & $54(71)$ & $10(67)$ & & & & \\
\hline$>37.8$ & $22(29)$ & $5(33)$ & & & & \\
\hline Anemia & & & 0.096 & & & \\
\hline No & $39(51)$ & $4(27)$ & & & & \\
\hline Yes & $37(49)$ & $11(73)$ & & & & \\
\hline Leukopenia & & & $0.004^{*}$ & 11.64 & $1.15-117.93$ & $0.038^{*}$ \\
\hline No & 70 (92) & $9(60)$ & & & & \\
\hline Yes & $6(8)$ & $6(40)$ & & & & \\
\hline Thrombocytopenia & & & $0.030^{*}$ & 267.60 & $0.44-161,993.5$ & 0.087 \\
\hline No & $74(97)$ & $12(80)$ & & & & \\
\hline Yes & 2 (3) & $3(20)$ & & & & \\
\hline Bleeding tendency & & & $0.027^{*}$ & & & \\
\hline No & $74(100)$ & $13(87)$ & & & & \\
\hline Yes & $0(0)$ & $2(13)$ & & & & \\
\hline
\end{tabular}


Table 2. Continued

\begin{tabular}{|c|c|c|c|c|c|c|}
\hline \multirow{2}{*}{ Variable } & \multicolumn{2}{|c|}{ Univariate analysis } & \multirow{2}{*}{ P-value } & \multicolumn{2}{|c|}{ Multivariate analysis } & \multirow{2}{*}{ P-valu } \\
\hline & Survivors $(n=76)$ & Nonsurvivors $(n=15)$ & & Odd ratio & $95 \% \mathrm{Cl}$ & \\
\hline Acute kidney injury & & & $0.006^{*}$ & 43.17 & $0.633-2,944.2$ & 0.081 \\
\hline No & $74(97)$ & $11(73)$ & & & & \\
\hline Yes & $2(3)$ & $4(27)$ & & & & \\
\hline Hyponatremia & & & 0.757 & & & \\
\hline No & $54(71)$ & $10(67)$ & & & & \\
\hline Yes & $21(29)$ & $5(33)$ & & & & \\
\hline Hypokalemia & & & 0.110 & & & \\
\hline No & $67(89)$ & $11(73)$ & & & & \\
\hline Yes & $8(11)$ & $4(27)$ & & & & \\
\hline Tachypnea & & & 0.149 & & & \\
\hline $\mathrm{pCO}_{2} \geq 32$ & $63(84)$ & $10(67)$ & & & & \\
\hline $\mathrm{pCO}_{2}<32$ & $12(16)$ & $5(33)$ & & & & \\
\hline Cause of perforation & & & 0.280 & & & \\
\hline Benign cause & $45(59)$ & $12(80)$ & & & & \\
\hline Cancer & $7(9)$ & $2(13)$ & & & & \\
\hline latrogenic (CFS) & $16(21)$ & $0(0)$ & & & & \\
\hline Trauma & $4(5)$ & $0(0)$ & & & & \\
\hline Other & $4(5)$ & $1(7)$ & & & & \\
\hline Time from symptom onset to surgery (hr) & & & 0.275 & & & \\
\hline$<24$ & $43(70)$ & $5(50)$ & & & & \\
\hline$\geq 24$ & $18(30)$ & $5(50)$ & & & & \\
\hline Hemodynamic instability & & & $0.002^{*}$ & 1.73 & $0.11-27.19$ & 0.696 \\
\hline No & $68(89)$ & $8(53)$ & & & & \\
\hline Yes & $8(11)$ & $7(47)$ & & & & \\
\hline Feculent exudate & & & $0.004^{*}$ & 70.73 & $0.74-6,753.04$ & 0.067 \\
\hline No & $37(61)$ & $2(13)$ & & & & \\
\hline Yes & $23(39)$ & $11(87)$ & & & & \\
\hline Laparoscopic operation & & & 0.456 & & & \\
\hline Open method & $61(80)$ & $14(93)$ & & & & \\
\hline Laparoscopy & $15(20)$ & $1(7)$ & & & & \\
\hline Surgical site infection & & & 1.000 & & & \\
\hline No & $48(63)$ & $9(60)$ & & & & \\
\hline Yes & $28(37)$ & $6(40)$ & & & & \\
\hline Postoperative ileus & & & 0.546 & & & \\
\hline No & $56(74)$ & $10(67)$ & & & & \\
\hline Yes & $20(26)$ & $5(33)$ & & & & \\
\hline Body mass index $\left(\mathrm{kg} / \mathrm{m}^{2}\right)$ & $23.19 \pm 3.1$ & $23.25 \pm 3.6$ & 0.865 & & & \\
\hline White blood cell & $11.89 \pm 8.4$ & $9.14 \pm 8.6$ & 0.063 & & & \\
\hline Operative time (min) & $173.46 \pm 72.1$ & $218.33 \pm 69.8$ & $0.026^{\star}$ & 1.03 & $1.00-1.06$ & $0.041^{*}$ \\
\hline
\end{tabular}

Values are presented as number (\%) unless otherwise indicated.

$\mathrm{Cl}$, confidence interval; $\mathrm{pCO}_{2}$, partial pressure of carbon dioxide; $\mathrm{CFS}$, colonofiberscopy.

${ }^{*} \mathrm{P}<0.05$, statistically significant. 
Table 3. Comparison of perioperative findings and postoperative outcomes of HP versus other operative method in patients with moderate risk group of mortality

\begin{tabular}{|c|c|c|c|}
\hline Variable & $\begin{array}{l}\text { Other operative } \\
\text { method } \\
(n=19)\end{array}$ & $\begin{array}{l}\text { Hartmann's } \\
\text { procedure } \\
(n=30)\end{array}$ & P-value \\
\hline Age (yr) & & & 0.768 \\
\hline$\leq 70$ & $9(47)$ & $12(40)$ & \\
\hline$>70$ & $10(53)$ & $18(60)$ & \\
\hline Thrombocytopenia & & & 0.515 \\
\hline No & $19(100)$ & $28(93)$ & \\
\hline Yes & $0(0)$ & $2(7)$ & \\
\hline Bleeding tendency & & & 1.000 \\
\hline No & $19(100)$ & $28(97)$ & \\
\hline Yes & $0(0)$ & $1(3)$ & \\
\hline Acute kidney injury & & & 1.000 \\
\hline No & $18(95)$ & $29(97)$ & \\
\hline Yes & $1(5)$ & $1(3)$ & \\
\hline Feculent ascites & & & 0.744 \\
\hline No & $9(60)$ & $12(52)$ & \\
\hline Yes & $6(40)$ & $11(48)$ & \\
\hline Surgical site infection & & & 0.081 \\
\hline No & $14(74)$ & $14(47)$ & \\
\hline Yes & $5(26)$ & $16(53)$ & \\
\hline Postoperative ileus & & & 0.081 \\
\hline No & $12(63)$ & $26(87)$ & \\
\hline Yes & $7(37)$ & $4(13)$ & \\
\hline Mortality & & & 0.458 \\
\hline Survived & $17(89)$ & $24(80)$ & \\
\hline Died & $2(11)$ & $6(20)$ & \\
\hline Hospital stay (day) & & & 0.346 \\
\hline$\geq 15$ & $12(63)$ & $23(77)$ & \\
\hline$<15$ & $7(37)$ & 7 (23) & \\
\hline Cause of perforation & & & 0.130 \\
\hline Benign cause & $14(74)$ & $21(70)$ & \\
\hline Cancer & $1(5)$ & $7(23)$ & \\
\hline latrogenic & $2(11)$ & $0(0)$ & \\
\hline Trauma & $0(0)$ & $1(3)$ & \\
\hline Others & $2(11)$ & $1(3)$ & \\
\hline
\end{tabular}

Values are presented as a number (\%) unless otherwise indicated. HP, Hartmann's procedure.

with mortality of colonic perforation. Each study showed that the mortality of patients was associated with factors including but not limited to serum albumin level, C-reactive protein level, acute renal failure, Mannheim Peritoneal Index, and American Society of
Anesthesiologists physical status classification system score [2, 1114]. Scoring systems such as POSSUM, P-POSSUM, CR-POSSUM, Association of Coloproctology of Great Britain \& Ireland mortality model were developed to assess the prognosis of colonic perforation. Despite the development of these scoring systems, the assessment and adjustment of an accurate scoring system for predicting the risk of postoperative mortality is still challenging [15-18]. In this study, the preoperative existence of leukopenia and longer operative time was significantly associated with mortality.

Moore et al. [19] reported inadequate paradoxical granulopoiesis suppression after torso trauma. Subsequently, several studies revealed that bone marrow suppression caused by sepsis induces neutropenia [20, 21]. Sepsis also causes T-cell immune paralysis, so the immunity of the patient continues to get worse [22]. Tanaka et al. [23] reported that mortality and anti-inflammatory cytokines in the leukopenia group were higher than those of the leukocytosis group. Therefore, leukopenia could be regarded as a potential prognostic factor associated with mortality in septic patients.

Longer operative time itself was not a risk factor for higher mortality, which could be the consequence of disease severity. In addition, operative time could be affected by the skills of each surgeon. Therefore, we did not regard longer operative time as an objective variable.

In this study, 14 patients with an iatrogenic cause received PR and another 2 patients received PA. HP was not performed in patients with iatrogenic conditions. In this group, 5 patients of 16 were operated 24 hours after the perforation. Four of them were treated with PR and one with PA. Iatrogenic causes did not show statistical significance in univariate analysis but showed a lower tendency for in-hospital mortality. Patients with iatrogenic conditions who underwent PR without diversion had less severe disease. PR was more often performed in patients with iatrogenic disease that caused perforation within a few hours, no hemodynamic instability, and no feculent ascites. We excluded patients who underwent PR only because of mild disease to eliminate bias in our subanalysis. There were 8 cases of mortality in the subanalysis and 2 of them were operated with procedures other than HP (PR with diversion and PA with diversion). These 2 patients expired because of worsening sepsis on the sixth and fifth postoperative days.

Despite advancements in the surgical technique, HP is still a frequently performed operation for the treatment of left colonic perforation [24]. Since the mid-2000s, there have been many discussions on the proper surgical management for colonic diverticular perforation, but there is still controversy [25]. In a systematic review and meta-analysis by Halim et al. [7], 22 of 25 articles reported that PA was associated with lower in-hospital mortality than HP, however, the other 3 articles did not report this finding. Statistically, PA had lower in-hospital mortality than HP. However, because PA has a longer operative time, HP seemed to be a 
safer option for high-risk comorbid patients. Our subanalysis showed no statistically significant difference between HP and PR with diversion or PA in mortality among patients without leukopenia. According to our results and considering the QoL of the patients, surgical methods other than HP could be a better option for patients without leukopenia.

The reversal of HP is associated with its own mortality and morbidity. Many patients who underwent HP could not undergo the reversal operation because of their general condition or existence of malignancy. Many studies have evaluated the postoperative outcomes of the reversal of HP. In a review by Horesh et al. [3], the reversal rate varied but tended to be less than $50 \%$. Furthermore, some studies reported postoperative morbidity of more than $40 \%$ of the complication rate $[26,27]$. Recently, there have been active discussions about the safety of laparoscopic HP and the laparoscopic reversal of HP, and most studies have shown no significant difference in mortality between the laparoscopic method and open method [4, 28, 29]. We also started to perform these surgical methods in recent years. We experienced the same result: no significant difference in mortality between laparoscopic surgery versus the open method. This change in the surgical technique could be another bias.

Our study has some limitations. First, it was a single-center study and the sample size was relatively small. The validity of the results could be affected. Second, our study had a retrospective design, so we could not obtain some information, such as the Creactive protein level, procalcitonin level, and Acute Physiologic Assessment and Chronic Health Evaluation score. Finally, surgeries were performed by 10 different surgeons. However, there was no significant difference in postoperative outcomes by each surgeon.

In conclusion, the existence of leukopenia could be an objective prognostic factor for left colonic perforation. Considering the difficulties of HP reversal and the life quality of the patient, PR with diversion and PA with or without diversion may be suggested as an alternative option for left colonic perforation patients without leukopenia. A prospective controlled randomized study may be needed.

\section{CONFLICT OF INTEREST}

No potential conflict of interest relevant to this article was reported.

\section{REFERENCES}

1. Ng HJ, Yule M, Twoon M, Binnie NR, Aly EH. Current outcomes of emergency large bowel surgery. Ann R Coll Surg Engl 2015;97: 151-6.

2. Kriwanek S, Armbruster C, Beckerhinn P, Dittrich K. Prognostic factors for survival in colonic perforation. Int J Colorectal Dis 1994;9:158-62.
3. Horesh N, Rudnicki Y, Dreznik Y, Zbar AP, Gutman M, Zmora O, et al. Reversal of Hartmann's procedure: still a complicated operation. Tech Coloproctol 2018;22:81-7.

4. Toro A, Ardiri A, Mannino M, Politi A, Di Stefano A, Aftab Z, et al. Laparoscopic reversal of Hartmann's procedure: state of the art 20 years after the first reported case. Gastroenterol Res Pract 2014;2014:530140.

5. Vermeulen J, Gosselink MP, Busschbach JJ, Lange JF. Avoiding or reversing Hartmann's procedure provides improved quality of life after perforated diverticulitis. J Gastrointest Surg 2010;14:651-7.

6. Richards CH, Roxburgh CS; Scottish Surgical Research Group (SSRG). Surgical outcome in patients undergoing reversal of Hartmann's procedures: a multicentre study. Colorectal Dis 2015; 17:242-9.

7. Halim H, Askari A, Nunn R, Hollingshead J. Primary resection anastomosis versus Hartmann's procedure in Hinchey III and IV diverticulitis. World J Emerg Surg 2019;14:32.

8. World Health Organization, Haemoglobin concentrations for the diagnosis of anaemia and assessment of severity. Vitamin and Mineral Nutrition Information System. Geneva (Switzerland): World Health Organization; 2011.

9. Singer M, Deutschman CS, Seymour CW, Shankar-Hari M, Annane D, Bauer M, et al. The Third International Consensus Definitions for Sepsis and Septic Shock (Sepsis-3). JAMA 2016;315: 801-10.

10. Williamson DR, Albert M, Heels-Ansdell D, Arnold DM, Lauzier F, Zarychanski R, et al. Thrombocytopenia in critically ill patients receiving thromboprophylaxis: frequency, risk factors, and outcomes. Chest 2013;144:1207-15.

11. Tan KK, Zhang J, Liu JZ, Shen SF, Earnest A, Sim R. Right colonic perforation in an Asian population: predictors of morbidity and mortality. J Gastrointest Surg 2009;13:2252-9.

12. Shin R, Lee SM, Sohn B, Lee DW, Song I, Chai YJ, et al. Predictors of morbidity and mortality after surgery for intestinal perforation. Ann Coloproctol 2016;32:221-7.

13. Tan KK, Hong CC, Zhang J, Liu JZ, Sim R. Predictors of outcome following surgery in colonic perforation: an institution's experience over 6 years. J Gastrointest Surg 2011;15:277-84.

14. Bielecki K, Kamiński P, Klukowski M. Large bowel perforation: morbidity and mortality. Tech Coloproctol 2002;6:177-82.

15. Yoo RN, Kye BH, Kim G, Kim HJ, Cho HM. Mortality risk factor analysis in colonic perforation: would retroperitoneal contamination increase mortality in colonic perforation? Ann Surg Treat Res 2017;93:203-8.

16. Tekkis PP, Prytherch DR, Kocher HM, Senapati A, Poloniecki JD, Stamatakis JD, et al. Development of a dedicated risk-adjustment scoring system for colorectal surgery (colorectal POSSUM). Br J Surg 2004;91:1174-82.

17. Prytherch DR, Whiteley MS, Higgins B, Weaver PC, Prout WG, Powell SJ. POSSUM and Portsmouth POSSUM for predicting mortality. Physiological and Operative Severity Score for the enUmeration of Mortality and morbidity. Br J Surg 1998;85:1217- 
20.

18. Leung E, McArdle K, Wong LS. Risk-adjusted scoring systems in colorectal surgery. Int J Surg 2011;9:130-5.

19. Moore FA, Peterson VM, Moore EE, Rundus C, Poggetti R. Inadequate granulopoiesis after major torso trauma: a hematopoietic regulatory paradox. Surgery 1990;108:667-74.

20. Bone RC, Sibbald WJ, Sprung CL. The ACCP-SCCM consensus conference on sepsis and organ failure. Chest 1992;101:1481-3.

21. Markwart R, Condotta SA, Requardt RP, Borken F, Schubert K, Weigel C, et al. Immunosuppression after sepsis: systemic inflammation and sepsis induce a loss of naïve T-cells but no enduring cell-autonomous defects in T-cell function. PLoS One 2014;9: e115094.

22. Jensen IJ, Sjaastad FV, Griffith TS, Badovinac VP. Sepsis-Induced T Cell Immunoparalysis: the ins and outs of impaired t cell immunity. J Immunol 2018;200:1543-53.

23. Tanaka H, Ikeda T, Ono S, Suda S, Ueno T. White blood cell counts have an impact on septic patient outcome followed by polymyxin-b immobilized fiber with direct hemoperfusion. Critical Care 2015:19(Suppl 1):128.
24. Cirocchi R, Trastulli S, Desiderio J, Listorti C, Boselli C, Parisi A, et al. Treatment of Hinchey stage III-IV diverticulitis: a systematic review and meta-analysis. Int J Colorectal Dis 2013;28:447-57.

25. Seah DW, Ibrahim S, Tay KH. Hartmann procedure: is it still relevant today? ANZ J Surg 2005;75:436-40.

26. Mazeh H, Greenstein AJ, Swedish K, Nguyen SQ, Lipskar A, Weber KJ, et al. Laparoscopic and open reversal of Hartmann's procedure--a comparative retrospective analysis. Surg Endosc 2009; 23:496-502.

27. Banerjee S, Leather AJ, Rennie JA, Samano N, Gonzalez JG, Papagrigoriadis S. Feasibility and morbidity of reversal of Hartmann's. Colorectal Dis 2005;7:454-9.

28. Turley RS, Barbas AS, Lidsky ME, Mantyh CR, Migaly J, Scarborough JE. Laparoscopic versus open Hartmann procedure for the emergency treatment of diverticulitis: a propensity-matched analysis. Dis Colon Rectum 2013;56:72-82.

29. Agaba EA, Zaidi RM, Ramzy P, Aftab M, Rubach E, Gecelter G, et al. Laparoscopic Hartmann's procedure: a viable option for treatment of acutely perforated diverticultis. Surg Endosc 2009; 23:1483-6. 